\title{
Stability of Salvia fruticosa Mill. polyphenols and antioxidant activity in a citrate-based natural deep eutectic solvent
}

\author{
Spyros Grigorakis ${ }^{1,2}$, Abedalghani Halahlah ${ }^{1}$ and Dimitris P. Makris ${ }^{3, 凶}$ \\ ${ }^{1}$ Department of Food Science \& Nutrition, School of Environment, University of the Aegean, Mitr. Ioakim Street, Myrina \\ 81400, Greece \\ ${ }^{2}$ Food Quality \& Chemistry of Natural Products, Mediterranean Agronomic Institute of Chania (M. A. I. Ch.), International \\ Centre for Advanced Mediterranean Agronomic Studies (CIHEAM), P.O. Box 85, Chania 73100, Greece \\ ${ }^{3}$ Green Processes \& Biorefinery Group, Department of Food Science \& Nutrition, School of Agricultural Sciences, University \\ of Thessaly, N. Temponera Street, Karditsa 43100, Greece
}

\section{Article info}

Article history:

Received: $10^{\text {th }}$ July 2020

Accepted: $14^{\text {th }}$ September 2020

\section{Keywords:}

Antioxidant activity

Deep eutectic solvents

Polyphenols

Salvia fruticosa

Stability

\begin{abstract}
In a previous study, it was demonstrated that a novel deep eutectic solvent (DES), composed of lactic acid and sodium citrate dibasic at a molar ratio of 15:1 (LASCDB15), was a high-performing system with regard to polyphenol extraction from the medicinal plant Salvia fruticosa Mill. (Greek or Cretan sage). However, an issue of particular importance that should be addressed is the stability of the extract in this novel liquid since the information available to-date on extract stability in DES is rather limited and inconclusive. In this frame, this study was undertaken to generate extracts of $S$. fruticosa with LA-SCDB15 (a 77/23 w/w mixture of DES with water) and examine their stability in this solvent. $S$. fruticosa extracts exhibited remarkable stability under both accelerated and long-term conditions, and the antiradical activity and the ferric-reducing power of the extracts were shown to suffer virtually trivial modifications. Further analytical examination with liquid chromatography-diode array-tandem mass spectrometry assured that the major polyphenolic phytochemicals occurring in Salvia fruticosa extracts underwent non-significant changes and remained practically intact. It was concluded that the neoteric DES LASCDB15 may provide outstanding stability in polyphenol-containing extracts and its testing on other plant extracts is proposed as a further step towards revealing its stabilizing potential.
\end{abstract}

(c) University of SS. Cyril and Methodius in Trnava

\section{Introduction}

A high number of populations around the globe routinely utilize medicinal and aromatic plants (MAPs) as folk medical agents, but also food, for centuries. Currently, sound scientific data form a solid ground to support the pharmacological and nutritional attributes of MAPs and substantiate health claims and functionality (Anton et al. 2019). The ongoing interest for MAPs and MAP-based commodities derives from consumer demands for natural products with functional properties, which has stimulated a large development of neoteric botanical-based ingredients for foods, pharmaceutical and cosmetics (Campa and Baron 2018; Colombo et al. 2020). S. fruticosa Mill., otherwise known as $S$. triloba (Greek or Cretan sage) is a Lamiaceae species widely distributed in the East Mediterranean. Several bioactivities have been attributed to this medicinal plant, which 
are mainly due to its polyphenolic substances (Exarchou et al. 2015; Sarrou et al. 2016). Yet, to-date the implementation of green extraction methodologies to produce of polyphenol-enriched extracts from $S$. fruticosa is very limited.

Deep eutectic solvents (DES) are novel liquids composed of inexpensive, benign and reusable materials, embracing natural compounds, such as organic acids and their salts, polyols, amino acids etc. Usually, DES are composed of two constituents, one that functions as hydrogen bond acceptor (HBA) and another one as hydrogen bond donor (HBD), while DES synthesis is of low-cost, simple, and fast. Major intrinsic characteristics of DES are the tunability of composition to achieve water (im)miscibility, the low vapor pressure, and the absence of flammability, which make DES ideal solvents for a range of green processes (Espino et al. 2018). By virtue of their peculiar properties, DES have currently become the choice of preference for the effective extraction of numerous natural products, but important issues pertaining to extract stability in DES are presently poorly addressed.

Polyphenols are inherently molecules prone to oxidation and/or other structural modifications, and thus the study of polyphenol stability under a given set of conditions is of paramount importance. Recently, our group reported the use of a novel DES, coded LA-SCDB15, which displayed very high performance in the extraction of polyphenols from $S$. fruticosa (Grigorakis et al. 2020b). To further appraise the applicability of this solvent in the generation of polyphenolenriched extracts, this study was undertaken to examine the stability of $S$. fruticosa polyphenols in extracts produced using LA-SCDB15. Stability was assessed by monitoring the antiradical activity and the ferric-reducing power of the extracts, by employing an accelerated and a long-term test, at various temperatures. Moreover, to better illustrate the effect of extract storage in LA-SCDB15, liquid chromatographydiode array-tandem mass spectrometry (LC-DADMS/MS) analyses were also performed, to trace changes in major polyphenolic phytochemicals.

\section{Experimental}

\section{Chemicals}

All chromatographic analyses were accomplished with solvents of HPLC grade. L-lactic acid $(80 \%)$ was from Fisher Scientific (Loughborough, UK). Sodium citrate dibasic sesquihydrate (> $99 \%$ ), rosmarinic acid ( $\geq 98 \%$ ), gallic acid (97\%), sodium carbonate $(\geq 99.5 \%)$, ascorbic acid $(\geq 99 \%)$, sodium acetate trihydrate $(\geq 99.5 \%)$, luteolin 7-O-glucoside $\quad(\geq \quad 98 \quad \%)$, 2,2-diphenylpicrylhydrazyl (DPPH) $\quad(95 \quad \%)$ and chlorogenic acid $(\geq 95 \%)$ were from SigmaAldrich (Darmstadt, Germany). Folin-Ciacalteu reagent was from Merck (Darmstadt, Germany). 2,4,6-Tripyridyl-s-triazine (TPTZ) (98\%), acetic acid, methanol and iron chloride hexahydrate were from Honeywell/Fluka (Steinheim, Germany). The deep eutectic solvent (DES), composed of lactic acid (LA) and sodium citrate dibasic (SCDB) at a molar ratio of $15: 1$, was synthesized as described earlier (Grigorakis et al. 2020b). The DES was used as aqueous mixture $(77 / 23 \mathrm{w} / \mathrm{w})$.

\section{Plant material}

Certified $S$. fruticosa was provided by a botanicals store (Chania, Greece). The specimen composed of the aerial parts of the plant and it was received in dried form, in hermetically closed plastic packaging. Upon receipt, the plant material was pulverized in a table mill (Tristar, Tilburg, The Netherlands), as described previously (Grigorakis et al. 2020a) and stored under refrigeration $\left(4^{\circ} \mathrm{C}\right)$.

\section{Preparation of polyphenol extracts}

Extraction of $S$. fruticosa was performed using the optimized process, as reported elsewhere (Grigorakis et al. 2020b). In short, $0.375 \mathrm{~g}$ of dried plant material was mixed with $15 \mathrm{~mL} 77 \%$ (w/w) DES/water and ultrasonicated for $15 \mathrm{~min}$ in an ultrasonication bath (Sonorex Bandeline, Berlin, Germany), at room temperature $\left(23 \pm 2{ }^{\circ} \mathrm{C}\right)$. The ultrasonication settings were: power, $120 \mathrm{~W}$; frequency, $100 \mathrm{~Hz}$; acoustic energy density, 
120 W.L ${ }^{-1}$. After ultrasonication, which was the pretreatment stage, batch stirred tank extraction was carried out at a stirring speed $\left(\mathrm{Ss}_{\mathrm{s}}\right)$ of $900 \mathrm{rpm}$, at $80{ }^{\circ} \mathrm{C}$, for $150 \mathrm{~min}$. The extract thus obtained was centrifuged for $10 \mathrm{~min}$ at $10,000 \times g$ and the transparent supernatant was used for stability tests.

\section{Determination of the antiradical activity $\left(A_{A R}\right)$}

The assay was performed with a stoichiometric methodology, using DPPH (Cevalos-Casals and Cisneros-Zevallos 2003; Athanasiadis et al. 2017). The total stoichiometries $\left(n_{\mathrm{t}}\right)$ of the reaction between DPPH and polyphenols in the extract were determined using the following Eq. 1:

$n_{\mathrm{t}}=\frac{\mathrm{A}_{0}-\mathrm{A}_{\mathrm{f}}}{\varepsilon C_{\mathrm{TP}}}$

Where $C_{\mathrm{TP}}$ is the total polyphenol concentration of the extracts (mg.L $\left.{ }^{-1}\right), \quad \varepsilon \quad(\mathrm{DPPH})=$ $11,126 \times 10^{-6} \mu \mathrm{M}^{-1} \cdot \mathrm{cm}^{-1}, A_{0}$ is the $\mathrm{A}_{515}$ at $t=0$ and $A_{f}$ is the $A_{515}$ at $t=30 \mathrm{~min}$. Results were expressed as $\mu \mathrm{mol}$ DPPH per mg total polyphenols. For all measurements, an HP 8452A diode-array spectrophotometer was used.

\section{Determination of the ferric-reducing power $\left(P_{R}\right)$}

A previously published protocol was used (Karakashov et al. 2015). Briefly, volume of $0.05 \mathrm{~mL}$ of ferric chloride $(4 \mathrm{mM}$ in $0.05 \mathrm{M}$ $\mathrm{HCl}$ ) was combined with an equal volume of extract and the mixture was heated up at $37{ }^{\circ} \mathrm{C}$, in a water bath, for $30 \mathrm{~min}$. After incubation, $0.9 \mathrm{~mL}$ of TPTZ solution $(1 \mathrm{mM}$ in $0.05 \mathrm{M} \mathrm{HCl})$ was added and the mixture was allowed to stand at room temperature for another $10 \mathrm{~min}$. The absorbance at $620 \mathrm{~nm}$ was recorded using suitable control and results were reported as $\mathrm{mM}$ ascorbic acid equivalents (AAE).

\section{Total polyphenol concentration}

The methodology described elsewhere was implemented (Karakashov et al. 2015). In an Eppendorf tube of $1.5 \mathrm{~mL}$, volume of $0.02 \mathrm{~mL}$ extract, $0.78 \mathrm{~mL}$ deionized water and $0.05 \mathrm{~mL}$ Folin-Ciocalteu reagent were mixed and left to react for $2 \mathrm{~min}$, in the dark, at ambient temperature. Then, $0.15 \mathrm{~mL}$ of $20 \%$ sodium carbonate was added and the mixture was allowed to stand for $60 \mathrm{~min}$. A calibration curve constructed with gallic acid was used for quantification.

\section{Chromatography}

A method previously reported was used (Grigorakis et al. 2020a). A FinniganMAT P4000 pump coupled to a UV6000LP diode array detector (Thermo Scientific, Waltham, MA, U.S.A.), and a TSQ Quantum Access LC/MS/MS, equipped with a Surveyor pump (Thermo Scientific, Walltham, MA, U.S.A.), and controlled by XCalibur 2.1, TSQ 2.1 software, were employed. The column was Superspher RP-18, $125 \mathrm{~mm} \times 2 \mathrm{~mm}, 4 \mu \mathrm{m}$, kept at $40{ }^{\circ} \mathrm{C}$. The injection volume was $10 \mu \mathrm{L}$ and the eluents used were (A) $2.5 \%$ acetic acid and (B) methanol, operated at a flow rate of $0.3 \mathrm{~mL} \cdot \mathrm{min}^{-1}$. The gradient program was as follows: $0 \mathrm{~min}, 100 \%$ A; $22 \mathrm{~min}, 65 \% \mathrm{~A} ; 32 \mathrm{~min}, 65 \% \mathrm{~A} ; 60 \mathrm{~min}$, $0 \% \mathrm{~A} ; 65 \mathrm{~min}, 0 \% \mathrm{~A}$. Acquisition of mass spectra was done with negative ionization, employing sheath gas pressure $30 \mathrm{mTorr}$, auxiliary gas pressure 15 mTorr $\left(2 \times 10^{-5} \mathrm{bar}\right)$, collision pressure at 1.5 mTorr $\left(2 \times 10^{-6}\right.$ bar $)$ and capillary temperature $300{ }^{\circ} \mathrm{C}$. Quantification was performed using a calibration curve of luteolin 7-O-glucoside $\left(5-1,500 \mu \mathrm{g} . \mathrm{L}^{-1}, \mathrm{R}^{2}=0.9982\right)$, chlorogenic acid $\left(50-1,500 \mu \mathrm{g} \cdot \mathrm{L}^{-1}, \mathrm{R}^{2}=0.9986\right)$ and rosmarinic acid $\left(50-3,000 \mu \mathrm{g} . \mathrm{L}^{-1}, \mathrm{R}^{2}=0.9985\right)$. All standard solutions were prepared in HPLC grade methanol.

\section{Accelerated stability test}

A volume of extract $(20 \mathrm{~mL})$ was placed in a glass vial and heated up at 50,60, 70, 80 and $90{ }^{\circ} \mathrm{C}$ for $240 \mathrm{~min}$, by means of a heating magnetic stirrer (VELP Scientifica, NY, USA). Sampling was accomplished at 30-min intervals to assay antioxidant activity.

\section{Long-term stability test}

Equal volumes of extract $(20 \mathrm{~mL})$ were transferred into glass vials and stored in the fridge $\left(7^{\circ} \mathrm{C}\right)$, on the bench $\left(23 \pm 2{ }^{\circ} \mathrm{C}\right)$ and in a water bath adjusted at $40{ }^{\circ} \mathrm{C}$, for 30 days. During this period, 
special care was taken to avoid extract contact with light. Sampling was carried out at 3-days intervals to determine antioxidant activity.

\section{Statistical analysis}

Procedures were repeated twice, and determinations were carried out in triplicate. Values were given as averages \pm standard deviation (sd). Distribution analysis was carried out with JMPTM Pro 13 (SAS, Cary, NC, USA). Linear correlations were accomplished with SigmaPlot ${ }^{\mathrm{TM}}$ 12.5 (Systat Software Inc., San Jose, CA, USA).

\section{Results and Discussion}

\section{Accelerated stability test}

The objective of the test was to ascertain whether the antioxidant properties of the extract could be impacted as a result to exposure to a range of temperatures, varying from moderate $\left(50{ }^{\circ} \mathrm{C}\right)$ to severe $\left(90{ }^{\circ} \mathrm{C}\right.$ ) heating, for $240 \mathrm{~min}$, and thus to draw conclusions regarding extract stability in LA-SCDB15. The results of the test are depicted in Fig. 1. Over the range 50 to $80{ }^{\circ} \mathrm{C}$, the extract displayed by almost $17.5-21 \%$ higher $\mathrm{A}_{\mathrm{AR}}$ compared to the initial (untreated) sample. However, $A_{A R}$ declined to a level equal to the initial one, after heating at $90{ }^{\circ} \mathrm{C}$. Differences amongst values were shown to be non-significant $(p>0.05)$, which indicated that increases in temperature did not affect $\mathrm{A}_{\mathrm{AR}}$ to a significant extent. Furthermore, no consistent trend was observed in $\mathrm{A}_{\mathrm{AR}}$ as a response to temperature. Likewise, $P_{R}$ remained virtually intact since the differences found amongst the initial extract and the extracts treated at 50 to $90{ }^{\circ} \mathrm{C}$ varied between 0 and $3.1 \%$. This finding strongly suggested that LA-SCDB15 used to produce the extract, provided exceptional stability.

\section{Long-term stability test}

This test was employed to trace fluctuations in both $A_{A R}$ and $P_{R}$ during storage of the extract for 30 days, at different storage temperatures. As can be seen in Fig. 2, the $\mathrm{A}_{\mathrm{AR}}$ of the extract stored at $7{ }^{\circ} \mathrm{C}$ exhibited a significant decline by $39.9 \%$,
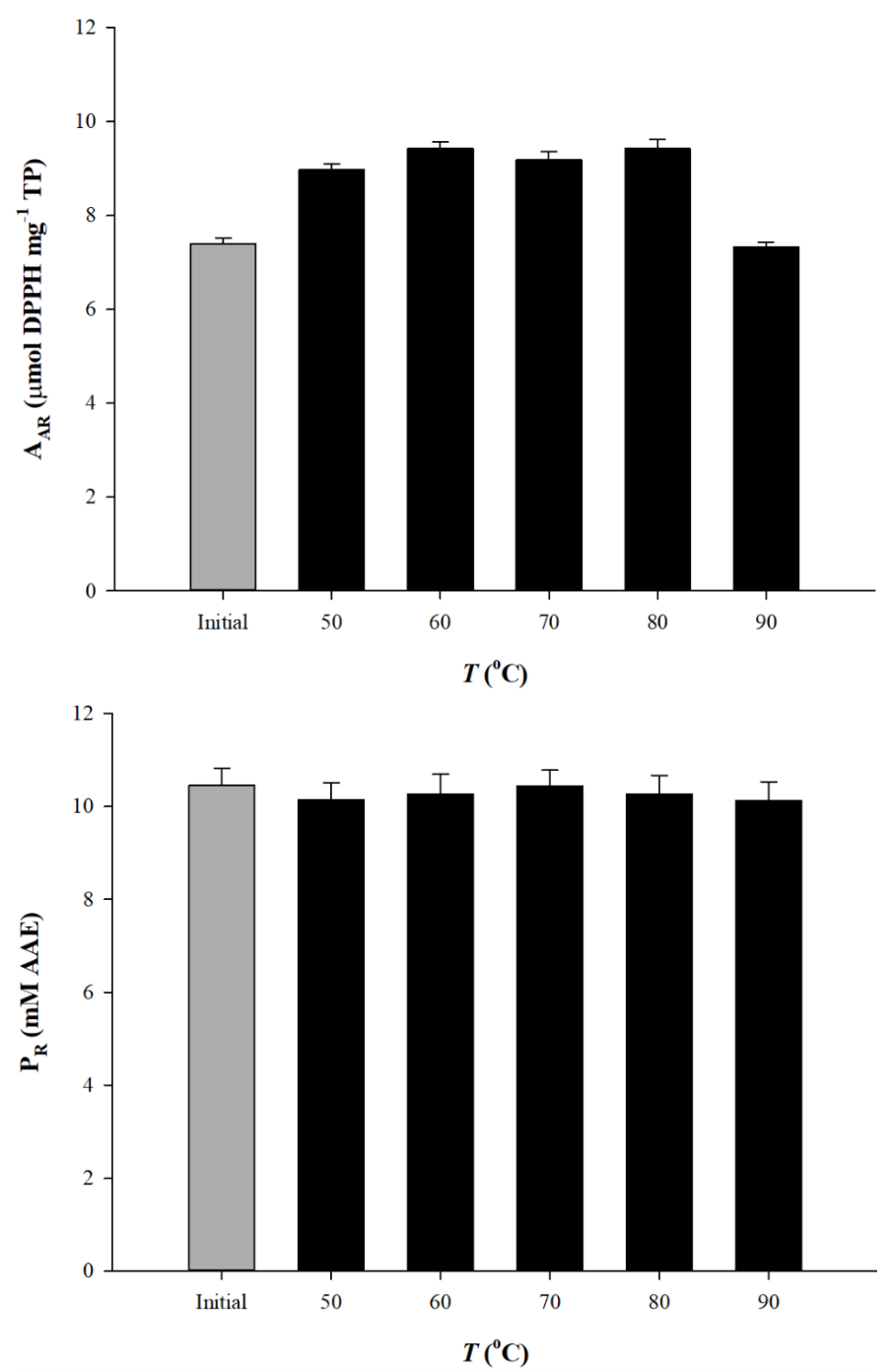

Fig. 1. Comparison of $A_{A R}$ (upper plot) and $P_{R}$ (lower plot) of $S$. fruticosa extracts, undergone no treatment (initial) and after treated at $50-90^{\circ} \mathrm{C}$, for $240 \mathrm{~min}$.

from 9.41 (day 0) to $5.66 \mu$ mol.DPPH.mg ${ }^{-1} \mathrm{TP}$ (day 12). However, $A_{A R}$ recovered to $8.91 \mu$ mol.DPPH.mg ${ }^{-1}$ TP by the end of the examination period (day 30). On the other hand, the extract stored at ambient conditions $\left(23{ }^{\circ} \mathrm{C}\right)$ displayed less intense variations and, after an increase to $9.87 \mu \mathrm{mol} . \mathrm{DPPH} . \mathrm{mg}^{-1} \mathrm{TP}(3.1 \%)$ at day 12 , it dropped to $8.10 \mu$ mol.DPPH. $\mathrm{mg}^{-1} \mathrm{TP}$ at day 30 .

The extract stored at $40 \quad{ }^{\circ} \mathrm{C}$ manifested a different pattern, as its $\mathrm{A}_{\mathrm{AR}}$ increased up to $10.16 \mu$ mol.DPPH.mg ${ }^{-1} \mathrm{TP}$ at day 15 , but it declined to $8.93 \mu \mathrm{mol}$.DPPH.mg ${ }^{-1} \mathrm{TP}$ at day 30 . Thus, at the end of the treatment the extracts had practically equal $A_{A R}$, irrespective of the storage temperature. The monitoring of $\mathrm{P}_{R}$ revealed a diversified time course than that seen with $\mathrm{A}_{\mathrm{AR}}$. 

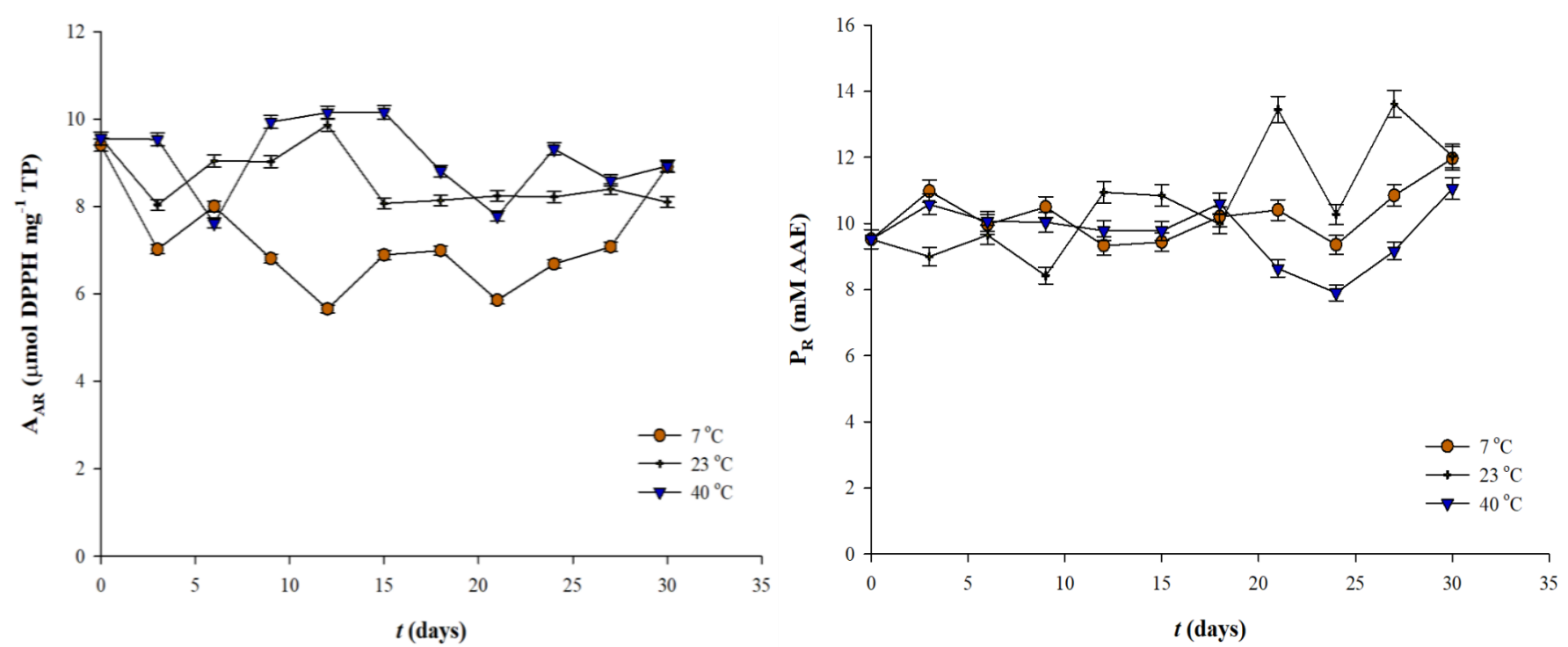

Fig. 2. Monitoring of $A_{A R}$ (left plot) and $P_{R}$ (right plot) of $S$. fruticosa extracts, stored at 7,23 and $40{ }^{\circ} \mathrm{C}$, for 30 days.

The pattern observed for the samples stored at 7 and $40{ }^{\circ} \mathrm{C}$ was almost identical, and at the end of the treatment, the extracts had $\mathrm{P}_{\mathrm{R}}$ of 11.97 and $11.07 \mathrm{mM}$ AAE, respectively. On the contrary, the extract stored at $23{ }^{\circ} \mathrm{C}$ showed rather large variations between day 18 and day 30, while its final level (day 30) was $12.04 \mathrm{mM}$ AAE. The difference amongst $P_{R}$ values at day 30 and the initial extract (9.53 mM AAE) was low and statistically non-significant $(p>0.05)$, which further confirmed the outstanding stability of the extract in LA-SCDB15.

Early studies evidenced that the antioxidant activity, as evaluated by $A_{A R}$ and $P_{R}$, might reflect changes associated with polyphenolic composition, such as oxidation (Sioumis et al. 2005). On the other hand, examinations on stability of polyphenol-containing extracts in DES are particularly limited, but the evidence emerged suggested that DES may provide improved stability over conventional solvents. Such an effect has been demonstrated for safflower (Carthamus tinctorius) pigments in a glucose-choline chloride DES (Dai et al. 2014) and Catharanthus roseus anthocyanins in a lactic acid-glucose DES (Dai et al. 2016). Long-term stability studies on Moringa oleifera extracts in a glycerol-sodium acetate DES showed that AAR displayed a constant decline over a 18-days storage period, at every temperature tested $\left(4,22\right.$ and $\left.50{ }^{\circ} \mathrm{C}\right)$, which obeyed pseudo-first order kinetics (Karageorgou et al. 2018). At $50{ }^{\circ} \mathrm{C}$, where the highest declining rate was found, polyphenols were extensively degraded, and the authors argued that this was the reason for the low AAR levels recorded at the end of the treatment. In that case, addition of hydroxypropyl $\beta$-cyclodextrin was found to slow down $A_{A R}$ drop. Similarly, olive leaf (Olea europaea) extracts in a glycerol-glycine DES showed a decreasing trend in $\mathrm{P}_{\mathrm{R}}$, which followed pseudo-zero order kinetics over a period of 20 days (Athanasiadis et al. 2018), irrespective of the assay temperature $\left(4,22\right.$ and $\left.50{ }^{\circ} \mathrm{C}\right)$. The presence of methyl $\beta$-cyclodextrin delayed the progression of the phenomenon, yet at $50{ }^{\circ} \mathrm{C}$ some principal metabolites suffered extensive degradation and a novel yellow pigment was formed.

However, unlike investigations revealing a reduction in either $A_{A R}$ or $P_{R}$, other studies illustrated that there was no specific pattern regarding the evolution of antioxidant activity during storage. Monitoring of both $A_{A R}$ and $P_{R}$ of onion solid waste extracts produced with a glycerol-sodium propionate DES, for a period of 30 days at $22{ }^{\circ} \mathrm{C}$, showed that at the end of storage $A_{A R}$ was enhanced by $19 \%$, whereas $P_{R}$ was virtually unaffected (Stefou et al. 2019). At the same time, no major changes were observed in the polyphenolic profile of the extracts. On the other hand, olive leaf extracts in a lactic acid-ammonium acetate DES, containing $\beta$-cyclodextrin, displayed a striking increase in AAR by $100 \%$ after 30 days at $22{ }^{\circ} \mathrm{C}$, although in this case too, $\mathrm{P}_{\mathrm{R}}$ was stable and fluctuated within 

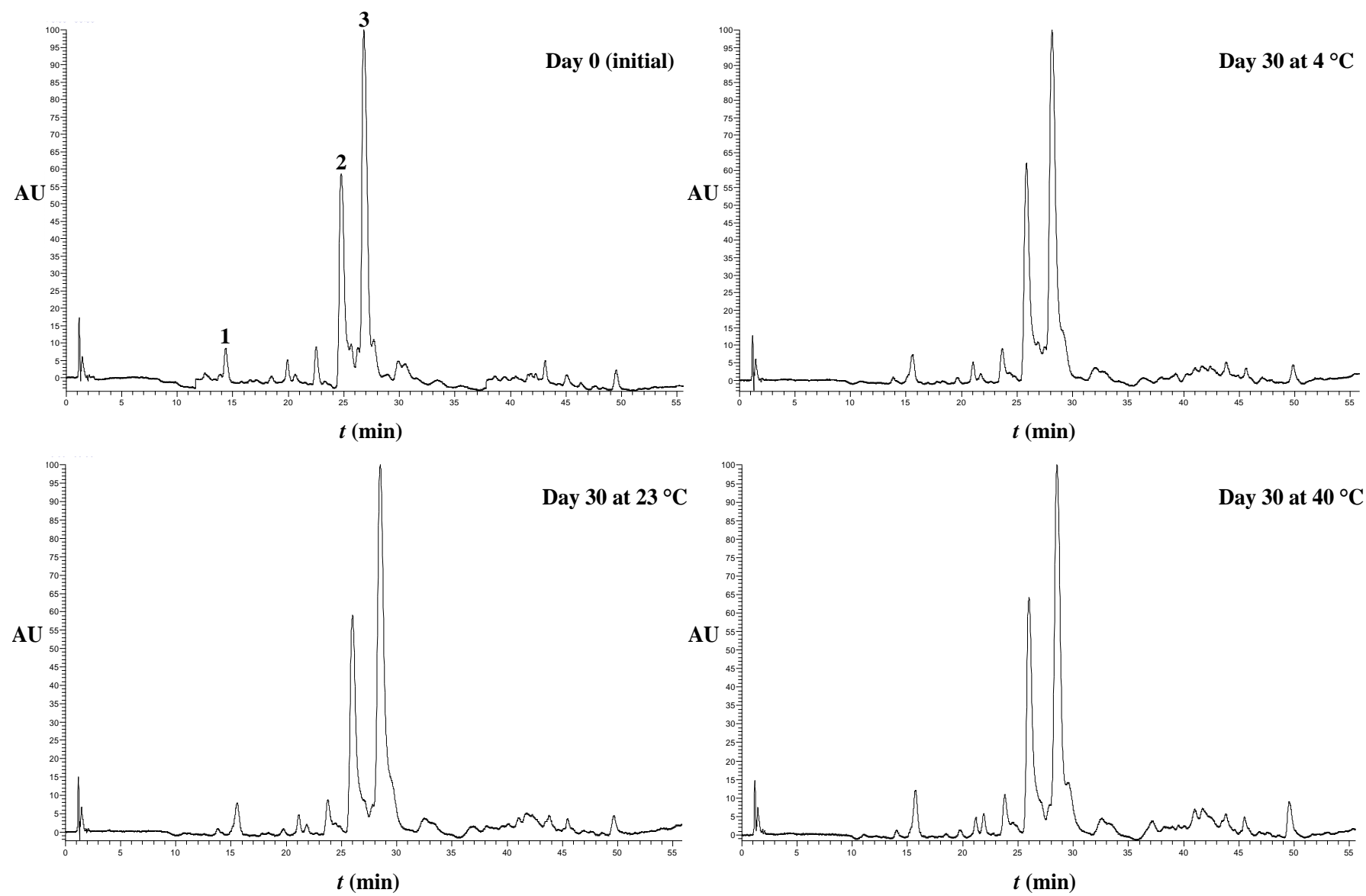

Fig. 3. Chromatograms of $S$. fruticosa extracts, obtained at $330 \mathrm{~nm}$, illustrating the effect of extract storage at different temperatures after 30 days, on the major polyphenolic compounds. Peak assignment: 1 - chlorogenic acid; 2 - luteolin 7-Oglucuronide; 3 - rosmarinic acid.

narrow limits (Chakroun et al. 2020). Paradoxically, the major polyphenols in the extract showed a decrease by $4.4-42 \%$. On the basis of the above-mentioned, it could be argued that both $A_{A R}$ and $P_{R}$ exhibited very high stability in LA-SCDB15, which has not been previously encountered for other extracts.

\section{Polyphenolic composition}

To shed more light onto the effect of LA-SCDB15 on the stability of $S$. fruticosa extracts, liquid chromatography-diode array-tandem mass spectrometry (LC-DAD-MS/MS) analyses were undertaken. The scope of this examination was the detection of alterations in the polyphenolic profile of the extracts stored at different temperatures, as well as quantitative changes in major polyphenolic phytochemicals. Chlorogenic acid and rosmarinic acid were identified by comparing the retention time and UV- vis spectra with those of authentic standards. Their identity was also confirmed by their respective pseudo-molecular ions at $\mathrm{m} / z=353$ and 359 . Luteolin 7-O-glucuronide was tentatively identified considering the pseudo-molecular ion at $\mathrm{m} / \mathrm{z}=461$ and the aglycone (luteolin) at $\mathrm{m} / \mathrm{z}=285$ (Grigorakis et al. 2020a).

The traces, recorded at $330 \mathrm{~nm}$, of the extracts stored at various temperatures $\left(7,23,40{ }^{\circ} \mathrm{C}\right)$, had identical polyphenolic profile and no major differences were seen (Fig. 3).

This outcome indicated neither extensive decomposition of any of the principal metabolites, nor the formation of any other substance, and evidenced the stability of the extract, irrespective of the storage temperature. To better portray possible changes in chlorogenic acid, luteolin 7-O-glucuronide and rosmarinic acid, brough about during storage, a quantitative investigation was also performed (Table 1). Storage at $7{ }^{\circ} \mathrm{C}$ resulted in a by $5.6 \%$ decrease in the sum 
Table 1. Quantitative data on changes occurred on major S. fruticosa polyphenols, after storage of extracts at different temperatures, after 30 days. Values given (mg.g ${ }^{-1}$ dry mass) represent means \pm standard deviation.

\begin{tabular}{lccrr}
\hline \multirow{2}{*}{ Compound } & \multicolumn{4}{c}{ Storage temperature } \\
\cline { 2 - 6 } & \multicolumn{1}{c}{ Initial } & $4{ }^{\circ} \mathrm{C}$ & $23{ }^{\circ} \mathrm{C}$ & $40{ }^{\circ} \mathrm{C}$ \\
\hline Chlorogenic acid & $0.085 \pm 0.002$ & $0.083 \pm 0.006$ & $0.085 \pm 0.005$ & $0.082 \pm 0.006$ \\
Luteolin 7- $O$-glucuronide & $5.99 \pm 0.17$ & $5.47 \pm 0.167$ & $5.25 \pm 0.31$ & $5.92 \pm 0.04$ \\
Rosmarinic acid & $14.67 \pm 0.33$ & $14.05 \pm 0.27$ & $13.25 \pm 0.33$ & $13.48 \pm 0.08$ \\
\hline Sum & 20.75 & 19.6 & 18.59 & 19.48 \\
\hline
\end{tabular}

of compounds, while at 23 and $40 \quad{ }^{\circ} \mathrm{C}$ the corresponding changes were 10.4 and $6.1 \%$. For all compounds considered, the modifications in their concentration found were limited and statistically non-significant, highlighting once again the extraordinary stability of the extract in LA-SCDB 15.

\section{Conclusions}

In the current examination, the stability of polyphenol-containing extract from the medicinal plant S. fruticosa in a novel DES termed as LA-SCDB15, was studied by deploying an accelerated and a long-term stability test. The accelerated test, performed over a range of temperatures varying from 50 to $90{ }^{\circ} \mathrm{C}$, provided substantial evidence for exceptional extract stability, since the antioxidant activity remained virtually unaffected upon treatment for $240 \mathrm{~min}$. The long-term test monitored antioxidant activity variations over a period of 30 days at various temperatures and assured that the extract suffered no major alteration in its antioxidant properties. A clear confirmation of stability emerged from LC-DADMS/MS analyses, which showed that the major polyphenols occurring in $S$. fruticosa extracts remained practically intact, irrespective of the storage temperature. The study demonstrated a remarkable stability of polyphenol extracts in the LA-SCDB15. The use of this neoteric solvent regarding effective extract storage remains to be elucidated for other plant materials too. This will confirm the polyphenol-stabilizing ability of this liquid and enable its wider applicability.

\section{Conflict of Interest}

The authors declare that they have no conflict of interest.

\section{References}

Anton R, Mathioudakis B, Pramono S, Sezik E, Sharma S (2019) Traditional use of botanicals and botanical preparations. Eur. Food Feed Law Rev. 14: 132-141.

Athanasiadis V, Grigorakis S, Lalas S, Makris DP (2018) Highly efficient extraction of antioxidant polyphenols from Olea europaea leaves using an eco-friendly glycerol/glycine deep eutectic solvent. Waste Biomass Valori. 9: 1985-1992.

Athanasiadis V, Lalas S, Makris DP (2017) Effect of methyl $\beta$-cyclodextrin on radical scavenging kinetics of olive leaf extracts and interactions with ascorbic acid. Chem. Engineering. 1: 6.

Campa M, Baron E (2018) Anti-aging effects of select botanicals: scientific evidence and current trends. Cosmetics 5: 54.

Cevallos-Casals BA, Cisneros-Zevallos L (2003) Stoichiometric and kinetic studies of phenolic antioxidants from Andean purple corn and red-fleshed sweetpotato. J. Agric. Food Chem. 51: 3313-3319.

Chakroun D, Grigorakis S, Loupassaki S, Makris DP (2019) Enhanced-performance extraction of olive (Olea europaea) leaf polyphenols using L-lactic acid/ammonium acetate deep eutectic solvent combined with $\beta$-cyclodextrin: screening, optimisation, temperature effects and stability. Biomass Convers. Biorefin.

Colombo F, Restani P, Biella S, Di Lorenzo C (2020) Botanicals in functional foods and food supplements: tradition, efficacy and regulatory aspects. Appl. Sci. 10: 2387.

Dai Y, Rozema E, Verpoorte R, Choi YH (2016) Application of natural deep eutectic solvents to the extraction of anthocyanins from Catharanthus roseus with high extractability and stability replacing conventional organic solvents. J. Chromatogr. A. 1434: 50-56.

Dai Y, Verpoorte R, Choi YH (2014) Natural deep eutectic solvents providing enhanced stability of natural colorants from safflower (Carthamus tinctorius). Food Chem. 159: 116-121.

Espino M, de los Ángeles Fernández M, Gomez FJ, Boiteux J, Silva MF (2018) Green analytical chemistry metrics: Towards a sustainable phenolics extraction from medicinal plants. Microchem. J. 141: 438-443.

Exarchou V, Kanetis L, Charalambous Z, Apers S, Pieters L, Gekas V, Goulas V (2015) HPLC-SPE-NMR characterization of major metabolites in Salvia fruticosa 
Mill. Extract with antifungal potential: Relevance of carnosic acid, carnosol, and hispidulin. J. Agric. Food Chem. 63: 457-463.

Grigorakis S, Benchennouf A, Halahlah A, Makris DP (2020a) High-performance green extraction of polyphenolic antioxidants from Salvia fruticosa using cyclodextrins: optimization, kinetics, and composition. Appl. Sci. 10: 3447.

Grigorakis S, Halahlah A, Makris DP (2020b) Batch stirredtank green extraction of Salvia fruticosa Mill polyphenols using newly designed citrate-based deep eutectic solvents and ultrasonication pretreatment. Appl. Sci. 10: 4774.

Karageorgou I, Grigorakis S, Lalas S, Makris DP (2018) The effect of 2-hydroxypropyl $\beta$-cyclodextrin on the stability of polyphenolic compounds from Moringa oleifera Lam leaf extracts in a natural low-transition temperature mixture. Nova Biotech. Chim. 17: 29-37.

Karakashov B, Grigorakis S, Loupassaki S, Makris DP (2015) Optimisation of polyphenol extraction from Hypericum perforatum (St. John's Wort) using aqueous glycerol and response surface methodology. J. Appl. Res. Med. Aromat. Plants 2: 1-8.

Paiva A, Craveiro R, Aroso I, Martins M, Reis RL, Duarte ARC (2014) Natural deep eutectic solvents-solvents for the $21^{\text {st }}$ century. ACS Sustainable Chem. Eng. 2: 10631071.

Sarrou E, Martens S, Chatzopoulou P (2016) Metabolite profiling and antioxidative activity of Sage (Salvia fruticosa Mill.) under the influence of genotype and harvesting period. Ind. Crops Prod. 94: 240-250.

Sioumis N, Kallithraka S, Tsoutsouras E, Makris DP, Kefalas $P$ (2005) Browning development in white wines: Dependence on compositional parameters and impact on antioxidant characteristics. Eur. Food Res. Technol. 220: 326-330.

Stefou I, Grigorakis S, Loupassaki S, Makris DP (2019) Development of sodium propionate-based deep eutectic solvents for polyphenol extraction from onion solid wastes. Clean Technol. Environ. Policy 21: 1563-1574. 